\title{
Spatial scales of interannual recruitment variations of marine, anadromous, and freshwater fish
}

\author{
R.A. Myers, G. Mertz, and J. Bridson
}

\begin{abstract}
We examine the spatial scale of variability in recruitment for 11 marine, three anadromous, and five freshwater species. Generally the spatial scale of recruitment correlations for marine species is approximately $500 \mathrm{~km}$, compared with less than $50 \mathrm{~km}$ for freshwater; anadromous species fall between these two scales. The scale for marine species is comparable with (but less than) that of the largest-scale environmental variables (and is compatible with the idea that large-scale environmental agents influence recruitment). Our results are consistent with the hypothesis that predation is a more important factor in determining recruitment in freshwater than it is in the marine environment.

Résumé : Nous avons examiné l'échelle spatiale de la variabilité du recrutement chez 11 espèces marines, trois espèces anadromes et cinq espèces d'eau douce. Généralement, l'échelle spatiale des corrélations de recrutement pour les espèces marines est d'environ $500 \mathrm{~km}$, comparativement à moins de $50 \mathrm{~km}$ pour les espèces d'eau douce; pour les espèces anadromes, l'échelle se trouvent entre les deux. L'échelle des espèces marines est comparable (mais inférieure) à celle des variables environnementales de la plus grande échelle (et concorde avec l'idée que des agents environnementaux à grande échelle influent sur le recrutement). Nos résultats concordent avec l'hypothèse que la prédation est un facteur plus important pour la détermination du recrutement en eau douce que dans l'environnement marin.

[Traduit par la Rédaction]
\end{abstract}

\section{Introduction}

The sources of recruitment variability in fish populations have yet to be definitively identified (see Wooster and Bailey 1989 for a recent review). The relative importance of biotic factors (food supply, predation) and abiotic factors (temperature, stratification, currents, etc.) remains uncertain. The spatial scale of recruitment variability should furnish information as to the processes involved because different forcing agents will be characterized by different spatial scales (Koslow et al. 1987; Mann 1993). To date, the spatial scale for recruitment variability has been evaluated explicitly for only one species, Atlantic cod (Gadus morhua) (Myers et al. 1995c), and there has not been an attempt to compare the scales for marine, anadromous, and freshwater species. This paper addresses these issues by presenting an analysis of the spatial scale for recruitment variability for all species (marine, anadromous, and freshwater) for which sufficient data were obtainable. We attempt to draw conclusions about the relative weight of biotic and abiotic influences in freshwater and marine systems.

\section{Methods and data}

We assembled over 500 time series of spawner abundance and

Received August 6, 1996. Accepted November 18, 1996. $\mathrm{J} 13593$

R.A. Myers, ${ }^{\mathbf{1}}$ G. Mertz, and J. Bridson. Department of Fisheries and Oceans, Northwest Atlantic Fisheries Center, Box 5667, St. John's, NF A1C 5X1, Canada.

1 Author to whom all correspondence should be addressed at Killam Chair in Ocean Studies, Department of Biology, Dalhousie University, Halifax, NS B3H 4J1, Canada. e-mail: Ransom.Myers@Dal.Ca recruitment for fish populations (Myers et al. 1990, 1995b) (Fig. 1). The data are available from the first author in digital form.

The marine stocks included Atlantic cod, haddock (Melanogrammus aeglefinus), Atlantic herring (Clupea harengus), Pacific ocean perch (Sebastes alutus), plaice (Pleuronectes platessa), pollock (Pollachius virens), sole (Solea vulgaris), walleye pollock (Theragra chalcogramma), and whiting (Merlangius merlangus). We also considered all North Atlantic redfish of the genus Sebastes in one comparison and hakes of the genus (Merluccius) in another.

For most marine populations, spawning stock biomass (SSB) and recruitment were estimated by sequential population analysis (SPA) of commercial catch-at-age data. SPA techniques include virtual population analysis, cohort analysis, and related methods that reconstruct population size from catch-at-age data (Hilborn and Walters 1992). For six of the redfish populations, recruitment was estimated from research trawl surveys.

Three anadromous Pacific salmon species were studied: chum (Oncorhynchus keta), pink (Oncorhynchus gorbuscha), and sockeye salmon (Oncorhynchus nerka). For Pacific salmon stocks, spawner abundance is the estimate of the number of upstream migrants discounted for mortality within the river and recruitment combines catch and the number of upstream migrants. For pink salmon, we also used 10 time series of research estimates of eggs that overwinter and of the number of young fish (fry) that emerge from the gravel and migrate downstream to the ocean the following spring. For sockeye salmon, we had access to 11 studies in which there were estimates of egg or fry production and subsequent smolt production. These estimates do not rely on commercial catch data and avoid the difficulty of stock separation that plagues the analysis of commercial catch data. Obviously, they only analyze survival during the freshwater part of the life cycle.

The freshwater stocks included brook trout (Salvelinus fontinalis), northern pike (Esox lucius), sauger (Stizostedion canadense), yellow perch (Perca flavescens), and walleye (Stizostedion vitreum). The seven brook trout populations were from introduced populations in California mountain lakes (De Gisi 1994); these populations were estimated using research gill nets and maximum likelihood depletion estimation. Recruitment was estimated for the northern pike, sauger, 
Fig. 1. Locations of populations used in the analysis.
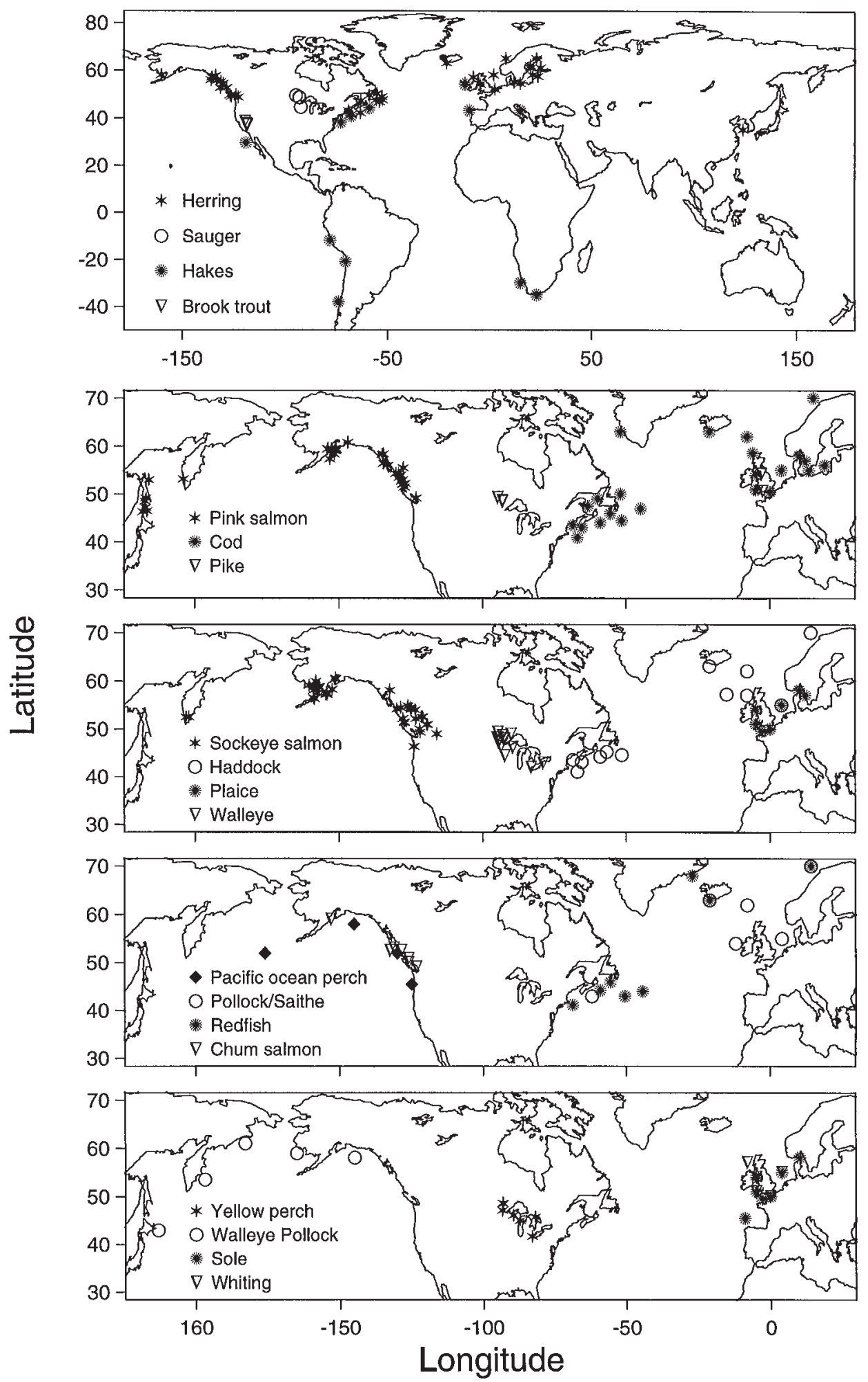

and walleye by research gill nets, trawling, or SPA (for two walleye populations). Estimates of year-class strength were averaged over several ages for the research gill nets or trawls to minimize estimation error.

We fit a Ricker model (Hilborn and Walters 1992) to the recruitment, $R$, and spawner abundance estimates, $S$ :
(1)

$$
R=\alpha S \mathrm{e}^{-\beta S}
$$

The residuals from this regression were used to find the correlation between stocks. Other stock recruitment models, e.g., the BevertonHolt (Hilborn and Walters 1992), were investigated and gave similar results. We also performed the correlation analysis for the logged 
Fig. 2. Correlation of recruitment between pairs of stocks, corrected for spawner abundance, versus distance between the stocks. Fits of the models $\mathrm{e}^{-\frac{d}{v}}$ (solid curve) and $\rho_{0} \mathrm{e}^{-\frac{1}{2}\left(\frac{d}{\sigma}\right)^{2}}$ (broken curve).

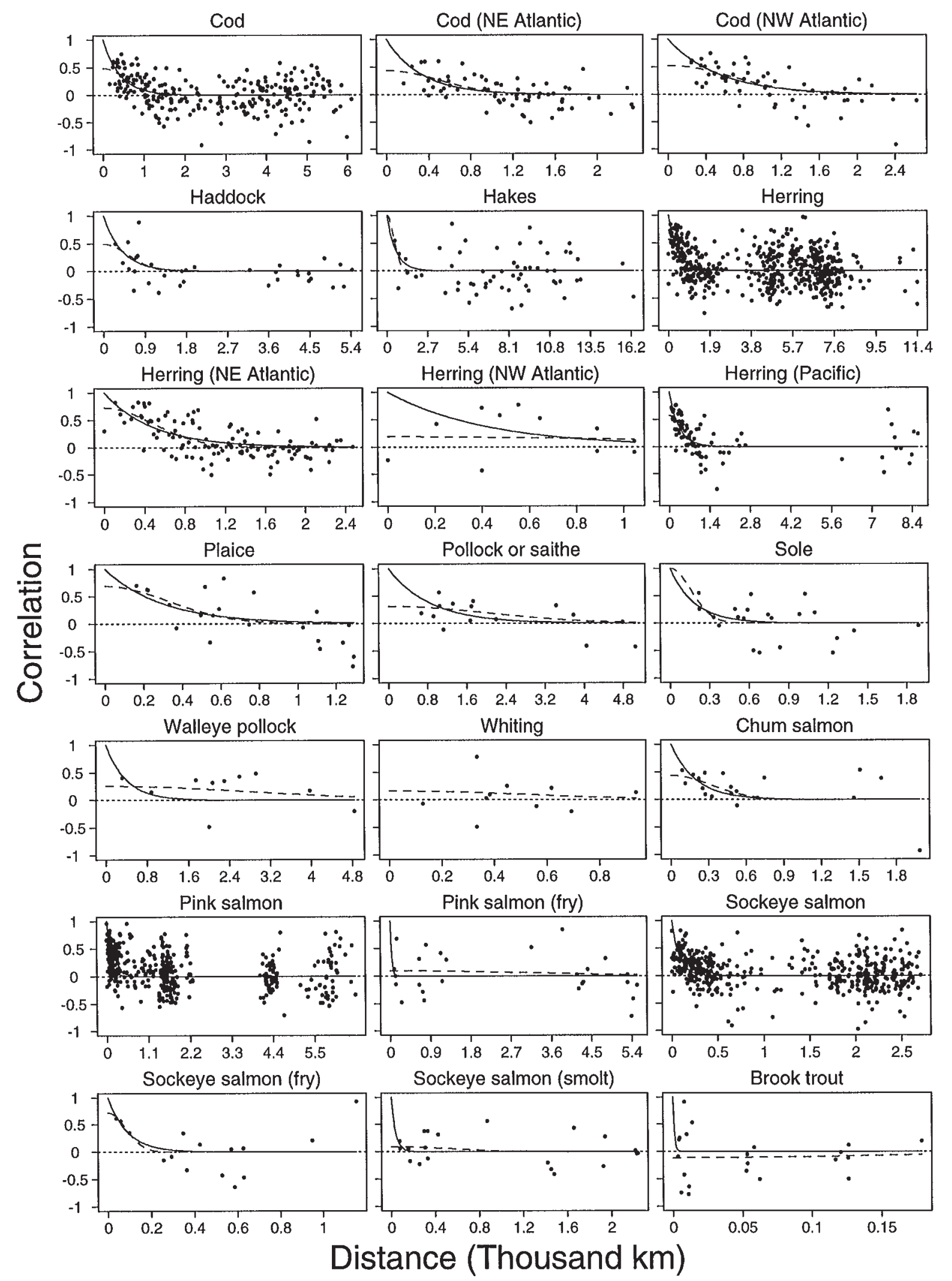


Table 1. For each species the parameters for two different fits are given when using Ricker model residuals to determine correlation.

\begin{tabular}{|c|c|c|c|c|c|c|c|}
\hline \multirow[b]{2}{*}{ Species } & \multirow[b]{2}{*}{$n$} & \multirow[b]{2}{*}{ df } & \multicolumn{2}{|c|}{$\mathrm{e}^{-\frac{d}{v}}$} & \multicolumn{3}{|c|}{$\rho_{1} \mathrm{e}^{-\frac{1}{2}\left(\frac{d}{\sigma}\right)^{2}}$} \\
\hline & & & $v$ & SS & $\rho_{1}$ & $\sigma$ & SS \\
\hline NE Atlantic & 12 & 65 & $330(45)$ & 2 & $0.44(0.1)$ & $500(110)$ & 1.9 \\
\hline NW Atlantic & 11 & 54 & $540(58)$ & 1.5 & $0.53(0.08)$ & $680(120)$ & 1.4 \\
\hline Haddock & 9 & 32 & $410(98)$ & 1.1 & $0.49(0.28)$ & $540(220)$ & 1.1 \\
\hline NE Atlantic & 16 & 108 & $490(48)$ & 4 & $0.73(0.08)$ & $480(53)$ & 3.6 \\
\hline NW Atlantic & 6 & 10 & $420(280)$ & 2.2 & $0.19(0.21)$ & $1300(5000)$ & 0.97 \\
\hline Pacific & 14 & 84 & $340(31)$ & 2.3 & $0.57(0.05)$ & $430(52)$ & 2.1 \\
\hline Plaice & 7 & 20 & $300(100)$ & 1.6 & $0.69(0.3)$ & $330(140)$ & 1.6 \\
\hline Pollock or saithe & 6 & 14 & $860(190)$ & 0.51 & $0.31(0.12)$ & $2000(1300)$ & 0.41 \\
\hline Pink salmon & 32 & 438 & $100(7.6)$ & 21 & $0.42(0.03)$ & $250(37)$ & 19 \\
\hline Egg to fry & 10 & 25 & $32(39)$ & 1.3 & $0.09(0.09)$ & $3200(5300)$ & 1.3 \\
\hline Sockeye salmon & 36 & 471 & $79(6.1)$ & 16 & $0.28(0.03)$ & $230(27)$ & 11 \\
\hline Egg to fry & 9 & 14 & $90(46)$ & 0.71 & $0.72(0.47)$ & $82(89)$ & 0.7 \\
\hline Egg to smolt & 11 & 19 & $38(22)$ & 0.57 & $0.09(0.12)$ & $520(2100)$ & 0.56 \\
\hline Brook trout & 7 & 20 & $0.95(3.5)$ & 3.6 & $-0.11(0.12)$ & $150(470)$ & 3.4 \\
\hline
\end{tabular}

Note: $n$ gives the number of stocks, df gives the degrees of freedom for a one-parameter fit, $v$ is the parameter (with SE) for the exponential decay fit, and $\rho_{1}$ and $\sigma$ (with SE) are the parameters for the Gaussian fit. The SS columns give the sum of squares for each model. An asterisk indicates whenever the constraint that $\rho_{1}$ be between 1 and -1 was invoked (reducing the second fit to a one-parameter fit). A unique estimate for the first model could not be found for whiting.

recruitment without adjustment for spawning biomass, which allows the inclusion of more stocks; the results were similar.

\section{Estimating spatial scale}

A simple estimate of the spatial scale is the distance over which the pairwise correlation between recruitment time series is reduced by a factor $\mathrm{e}^{-1}$, i.e., the exponential decay rate or the e-folding scale. That is, we fit the model

(2) $\quad \rho(d)=\rho_{0} \mathrm{e}^{-\frac{d}{v}}$

where $\rho_{0}$ is the correlation between two stocks at zero separation, $v$ is the e-folding scale, and $d$ is the great circle distance between spawning locations of each population (kilometres). In this model, we constrain $\rho_{0}$ to have an absolute value of 1 or less. However, we also fit the model with $\rho_{0}$ constrained to be 1 . We found that the model was rarely improved by estimating $\rho_{0}$; therefore, we will present only the results for $\rho_{0}$ constrained to be 1 .

Some data sets appear to have a "shoulder" at $d=0$; therefore, we fit the model

(3) $\quad \rho(d)=\rho_{1} \mathrm{e}^{-\frac{1}{2}\left(\frac{d}{\sigma}\right)^{2}}$

where $\sigma$ is the standard deviation of a normal distribution. These models were fit with nonlinear least squares weighted by the fraction of years for which the stocks had overlapping data. Pairs of stocks were only included if they had an overlap of at least 5 years.

\section{Results}

We initially fit the exponential model (eq. 2) with $\rho_{0}$ constrained to be 1 (Fig. 2; Table 1). The inclusion of the parameter $\rho_{0}$ in the model significantly improves the fit for only three species: haddock and pink and sockeye salmon ( $F$-test; $p<$ $0.01)$. These fits are not shown because they are very similar to the fits of eq. 3 .

The fitting of eq. 3 to the data usually yields a correlation scale similar to that of the exponential fit. Exceptions occur when the correlation scale is small for the the exponential model, and the Gaussian model estimates a large $\sigma$ and a small $\rho_{1}$, e.g., pink salmon egg to fry data. However, these estimates are never significantly different from zero and are best interpreted as showing that survival is essentially independent among populations. In some cases the "best" estimate of $\rho_{1}$ was greater than 1 ; in these cases, $\rho_{1}$ was constrained to be 1 , which is noted by an asterisk in the tables.

The correlation scale was similar if we did not correct for spawner abundance (Table 2). For six species, there were insufficient data on spawner abundance, so the correlation scale is shown only for the unadjusted recruitment (Fig. 3).

For the marine species, the exponential fit with distance to the decay of the pairwise correlation of the residuals from the spawner recruitment function between all pairs of stocks shows that the e-folding scale is typically about $500 \mathrm{~km}$ (Fig. 2; Table 1).

The apparent positive correlation across the Atlantic for Atlantic cod was investigated by Myers et al. (1995c) and was found to be caused by long-term trends in the data. Plaice appear to be negatively correlated at the largest spatial scales; however, this relationship does not appear to be statistically significant.

For Atlantic herring, there are two notable outliers at a distance of zero for which the correlation is negative (Fig. 2). 
Table 2. Same as Table 1 except the effect of spawner abundance is not removed.

\begin{tabular}{|c|c|c|c|c|c|c|c|}
\hline \multirow[b]{2}{*}{ Species } & \multirow[b]{2}{*}{$n$} & \multirow[b]{2}{*}{$\mathrm{df}$} & \multicolumn{2}{|c|}{$\mathrm{e}^{-\frac{d}{v}}$} & \multicolumn{3}{|c|}{$\rho_{1} \mathrm{e}^{-\frac{1}{2}\left(\frac{d}{\sigma}\right)^{2}}$} \\
\hline & & & $v$ & SS & $\rho_{1}$ & $\sigma$ & $\mathrm{SS}$ \\
\hline NE Atlantic & 12 & 65 & $430(64)$ & 3.4 & $0.67(0.15)$ & $460(91)$ & 3.3 \\
\hline NW Atlantic & 11 & 54 & $680(82)$ & 2.2 & $0.57(0.09)$ & $800(150)$ & 2.1 \\
\hline Haddock & 14 & 83 & $500(73)$ & 2.9 & $0.56(0.11)$ & $600(120)$ & 2.9 \\
\hline NE Atlantic & 16 & 108 & $490(52)$ & 5 & $0.63(0.09)$ & $530(70)$ & 4.8 \\
\hline NW Atlantic & 12 & 65 & $650(85)$ & 4.7 & $0.65(0.07)$ & $660(100)$ & 4.3 \\
\hline Pacific & 14 & 85 & $350(40)$ & 3.8 & $0.57(0.06)$ & $450(65)$ & 3.3 \\
\hline Pacific ocean perch & 4 & 5 & $930(250)$ & 0.084 & $1 *$ & $750(130)$ & 0.068 \\
\hline Plaice & 7 & 20 & $340(120)$ & 2.1 & $0.75(0.3)$ & $360(140)$ & 1.9 \\
\hline Whiting & 5 & 9 & $210(90)$ & 0.59 & $0.44(0.5)$ & $280(230)$ & 0.56 \\
\hline Chum salmon & 7 & 18 & $190(47)$ & 0.9 & $0.53(0.17)$ & $260(89)$ & 0.85 \\
\hline Pink salmon & 32 & 439 & $140(12)$ & 31 & $0.51(0.04)$ & $230(33)$ & 29 \\
\hline Egg to fry & 10 & 27 & $0.07(0.12)$ & $950(3400)$ & 1.3 & & \\
\hline Sockeye salmon & 36 & 476 & $180(11)$ & 20 & $0.47(0.03)$ & $290(26)$ & 18 \\
\hline Egg to fry & 8 & 11 & $52(28)$ & 0.63 & $0.49(0.46)$ & $83(130)$ & 0.61 \\
\hline Egg to smolt & 11 & 19 & $31(28)$ & 0.81 & $-0.09(0.19)$ & $240(690)$ & 0.81 \\
\hline Brook trout & 7 & 20 & $3.6(1.5)$ & 2.4 & $0.17(0.09)$ & $240(800)$ & 2.1 \\
\hline Walleye & 16 & 70 & $18(9.1)$ & 5.7 & $0.15(0.1)$ & $200(180)$ & 5.4 \\
\hline Pike & 6 & 5 & $15(10)$ & 0.58 & $1 *$ & $11(3.9)$ & 0.44 \\
\hline Sauger & 4 & 5 & $20(11)$ & 0.18 & $1 *$ & $14(3.8)$ & 0.18 \\
\hline
\end{tabular}

Note: A unique estimate for the first model could not be found for pink salmon in the fry stage.

These represent separate Atlantic herring stocks that spawn at different times of the year, i.e., spring- and summer-spawning Icelandic Atlantic herring and fall- and spring-spawning Atlantic herring in the Gulf of St. Lawrence. These populations will clearly be subject to different environmental forcings; we should not be surprised that they are different.

For pink and sockeye salmon during their freshwater life stages, there is very little spatial correlation in the interannual survival. The spatial scale of survival from spawner to recruit, with the inclusion of marine survival, is larger.

There are relatively less data for freshwater species; however, the pattern seen in the five species investigated is the same: the correlation scale is very small. For example, the correlation between brook trout populations is negative as often as it is positive (Fig. 3). This result is consistent with the small scale seen in the correlation of freshwater survival of pink and sockeye salmon.

Freshwater species, e.g., Eurasian perch (Perca fluviatilis) and pikeperch (Stizostedion lucioperca), that spawn and live in the freshwater margins of the Baltic have spatial scales of recruitment larger than those that we have estimated for freshwater species (Böhling et al. 1991; Lehtonen and Lappalainen 1995). Larvae reared in the freshwater margins of the Baltic may be swept into the interior of this sea, so that these species, in effect, dwell in a marine environment.

Wind and thermal forcing of the ocean by the atmosphere may account for the large correlation scale for recruitment in marine systems. The site-to-site correlation of annual air temperature anomalies versus separation for maritime weather stations of the Northwest Atlantic is shown in Fig. 4; the Gaussian fit indicates that the correlation scale $(\sigma)$ is $1100 \mathrm{~km}$, with a standard error of $59 \mathrm{~km}$ (and with $\rho_{1}=0.905, \mathrm{SE}=0.44$ ). Sea surface temperature (SST) anomalies in the Northwest Atlantic have essentially the same correlation scale, about $1000 \mathrm{~km}$ (Thompson et al. 1988). This similarity is expected because SST variations are strongly influenced by thermal and wind forcing of the atmosphere (e.g., Thompson et al. 1988). Also shown in Fig. 4 (broken curve) is the Gaussian fit (Gunst 1995) to correlations of annual air temperature anomalies versus site separation for the continental United States. The correlation scale is similar to that for the marine sites, demonstrating that freshwater systems are exposed to climate signals having about the same scale as those influencing oceanic domains.

\section{Discussion and conclusions}

A simple generalization is apparent from our data: the correlation scale for recruitment of marine species is typically $500 \mathrm{~km}$ whereas for freshwater species, it is less than $50 \mathrm{~km}$. This finding generalizes the conclusion of Myers et al. (1995c) who showed that the correlation scale for recruitment of Atlantic cod was about $500 \mathrm{~km}$. Our result for freshwater is not consistent with claims that recruitment in walleye is synchronous over a wide spatial scale, i.e., approximately 1000 km (Colby 
Fig. 3. Same as Fig. 2 for those species for which there were not sufficient data to correct for spawner abundance.

Pacific ocean perch
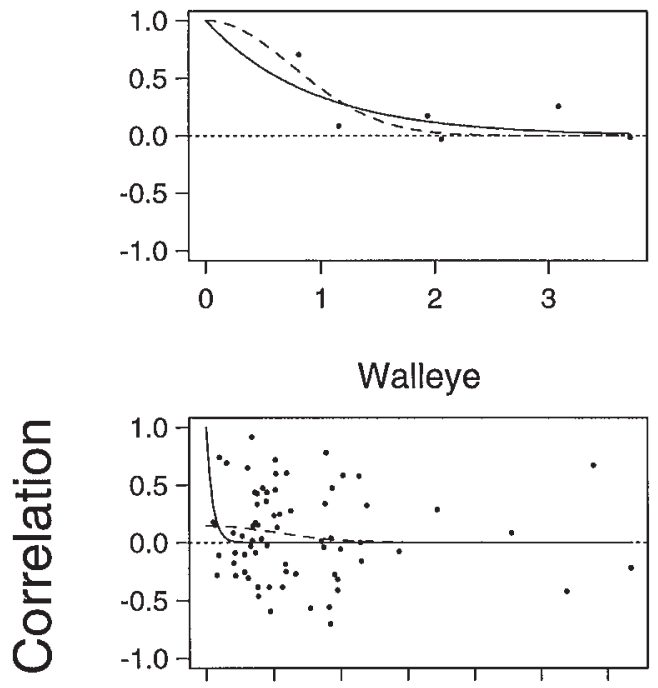

Walleye
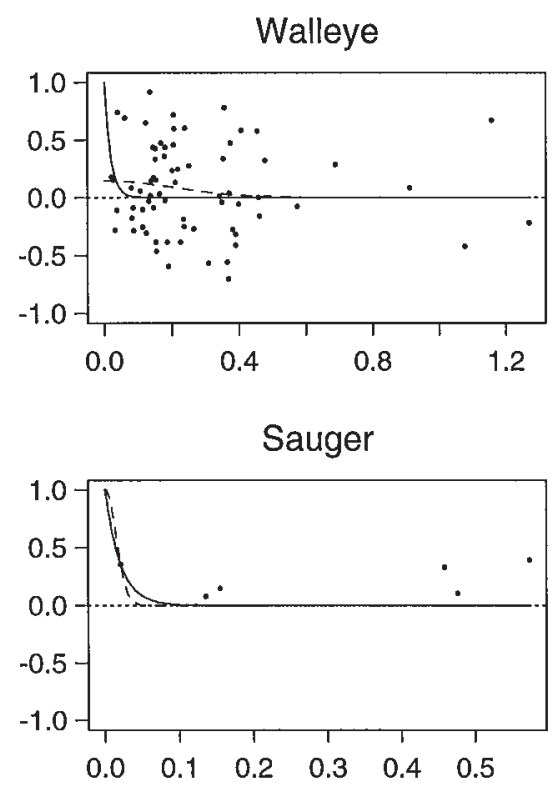

Redfish

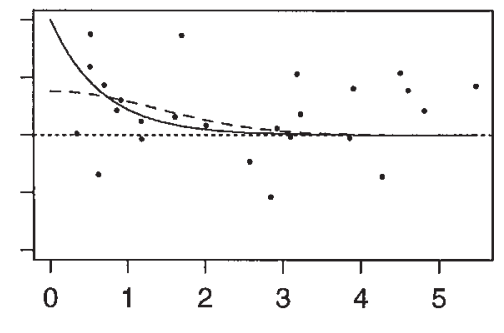

Pike

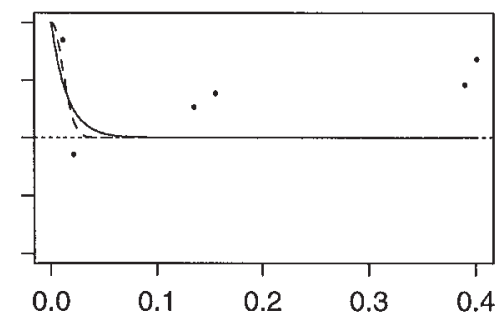

Yellow perch

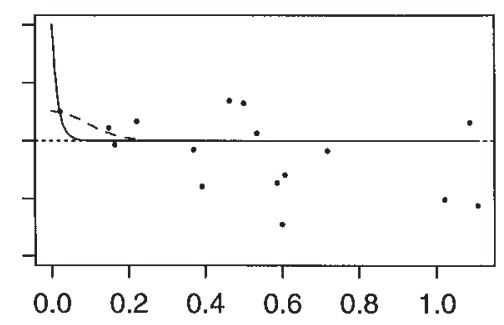

Distance (Thousand $\mathrm{km}$ )

et al. 1979). The previous conclusion regarding walleye was based on the observation that the 1959 year-class was strong in many lakes, and not on a statistical analysis.

We have found no evidence of large-scale (thousands of kilometres) patterns of recruitment for any species, despite previous surmises of such patterns, particularly for Pacific sardine (Sardinops sagax) (Kawasaki 1992). We attempted to examine Kawasaki's intriguing hypothesis with recruitment data for Pacific sardine (Kawasaki used catch data). Although we located data for six Pacific sardine stocks, the degree of overlap was not sufficient to give reliable estimates. We hope that Kawasaki's hypothesis can be fully tested at a later time. The absence of convincing transocean-scale correlations is consistent with the findings of Myers et al. (1995a).

It is possible that transocean-scale correlations are present with a lag. The hypothesis of lagged correlations in recruitment across the North Atlantic was examined by Myers et al. (1995a) who found that new data did not support the previously published lagged correlations identified by Templeman (1972). Researchers who may be interested in this, or any other problem, may have access to our database.

We have chosen to summarize the correlations between recruitment time series in the simpliest possible manner. However, there are species where a more detailed analysis is justified. For example, Myers et al. (1995c) separated the variability for Atlantic cod recruitment series into two components, low-frequency (periods greater than 10 years) and higher frequency variation, and demonstrated that the largescale variability was seen only in the former. These larger scale correlations seen for Atlantic cod (see Fig. 1) appear to be caused by artifactal trends. An analysis separating the lowfrequency and higher frequency variation may be important for some species. Again, our database is available to any researcher.

The existence of coherent recruitment fluctuations in marine systems on the order of $500 \mathrm{~km}$ suggests the influence of wind or SST because, in general, only these variables have sufficiently large correlation scales (about $1000 \mathrm{~km}$ ) to account for the synchronous component of recruitment. Displacements of the edge of the Gulf Stream occur in unison over distances of $1000 \mathrm{~km}$ or more (Drinkwater et al. 1994) and could account for synchronous recruitment variations in the Northwest Atlantic (only). The possible role of wind effects is attested to by the study of Koslow et al. (1987). They showed that the second principal component of atmospheric pressure (representing a particular wind pattern) had an apparent significant influence on recruitment for Atlantic cod stocks from Greenland to Nova Scotia. Unfortunately, one cannot be certain 
Fig. 4. Correlation of yearly air temperature anomalies between weather stations versus distance between stations (solid circles). Temperatures from maritime stations in the Northwest Atlantic from Godthaab, Greenland, to Cape Hatteras with over 50 years of data were used in the analysis (Drinkwater et al. 1994). We fit a Gaussian curve (solid curve) to the correlations as described in the text. We also plot (broken curve) the Gaussian fit, provided by Gunst (1995), to the correlation of annual U.S. air temperature anomalies (1951-1980) versus site separation. Note that different methods were used in the two analysis so that we do not claim that the two curves are different, only that the correlation scale in both cases is greater than $1000 \mathrm{~km}$.

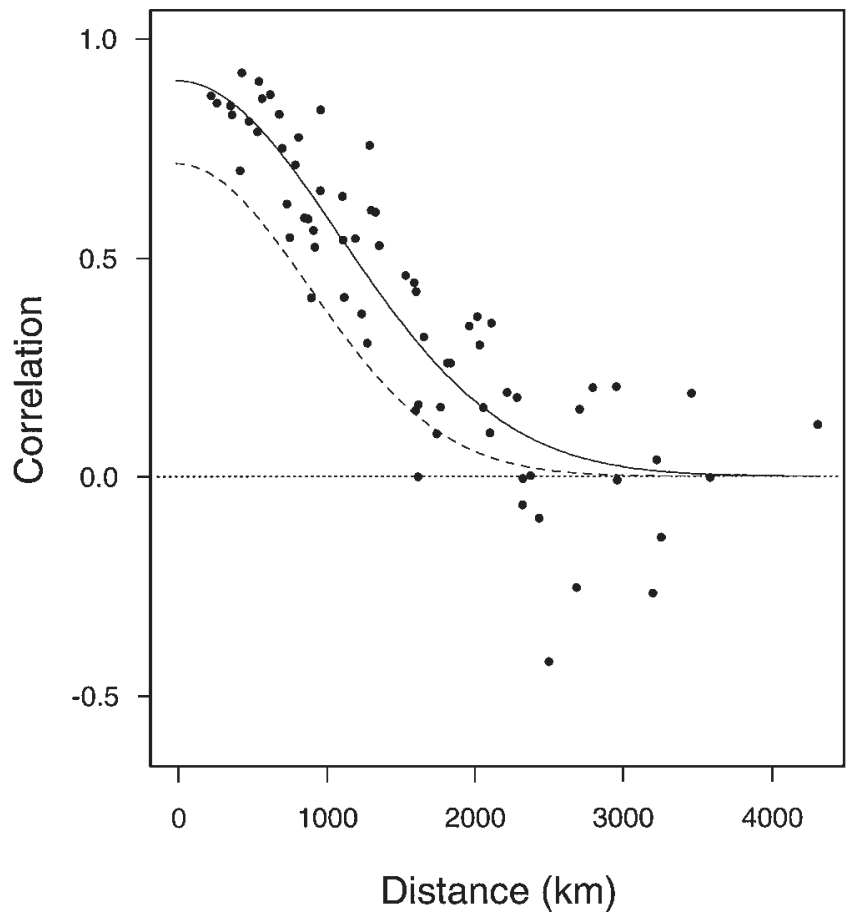

that this result is not an artifact of autocorrelation in the recruitment and environmental time series.

Lakes and streams are, like the oceans, exposed to very large-scale weather systems. For example, an advance or delay in vernal warming should cooccur at lakes separated by up to $1000 \mathrm{~km}$ (based on the correlation of air temperature anomalies in Fig. 4). Conceivably, these anomalies could affect the recruitment of spring-spawning species. On the other hand, lakes in quite close proximity to one another may exhibit unrelated patterns of temporal variation in certain chemical properties (Magnuson et al. 1990). Unfortunately, we cannot state with any certainty which variables are likely, in general, to exert the dominant influence.

As noted above, wind may impart large-scale synchrony to recruitment variations in marine systems. It is not clear that wind would have a similar effect in lakes. Small lakes may be sufficiently uniform that there are no unfavorable habitats into which the wind could drive eggs and larvae. (Fish stocks on oceanic shelfs are thought to suffer poor recruitment when eggs and larvae are exported to open ocean.) In shallow lakes, food supply for larvae may not change significantly when the wind mixes the water column, in contrast with the oceans, where wind mixing is thought to destroy the enhanced concentration of food at the pycnocline thought necessary to support some species of fish larvae (Lasker 1975).

An obvious difference between freshwater and oceanic systems is the size of the domains occupied by the fish stocks. The size factor may enter the picture when the influence of plankton patchiness on recruitment is considered. In oceanic regimes, eggs and larvae may be dispersed over a vast area, in effect averaging over a large number of patches. In contrast, in small lakes the recruitment variability associated with plankton patchiness may dominate (because there is little averaging over patches), thus masking large-scale influences.

Recruitment variability in freshwater may depend predominantly on biotic influences, particularly the predation by adults of one species on juveniles of another. Walleye predation has been shown to have a significant impact on year-class strength of yellow perch in Oneida Lake (Mills et al. 1987). In contrast, these effects have not been convincingly demonstrated in marine systems (Leggett and DeBlois 1994). Verity and Smetacek (1996) have conjectured that predation is a less dominant influence in marine systems because fish densities appear to be 10-1000 times smaller than in freshwater systems (Horn 1972).

\section{Acknowledgments}

We thank the many assessment biologists whose hard work make our analysis possible. We thank Nick Barrowman for programming assistance and $\mathrm{P}$. Pepin for providing valuable advice on the manuscript.

\section{References}

Böhling, P., Hudd, R., Lehtonen, H., Karås, P., Neuman, E., and Thoresson, G. 1991. Variations in year-class strength of different perch (Perca fluviatilis) populations in the Baltic Sea with special reference to temperature and pollution. Can. J. Fish. Aquat. Sci. 48: $1181-1187$.

Colby, P.J., McNicol, R.E., and Ryder, R.A. 1979. Synopsis of biological data on the walleye Stizostedion vitreum vitreum (Mitchill 1818). FAO Fish. Synop. No. 119.

De Gisi, J.S. 1994. Year class strength and catchability of mountain lake brook trout. Master's thesis, University of British Columbia, Vancouver, B.C.

Drinkwater, K.F., Myers, R.A., Pettipas, R.G., and Wright, T.L. 1994. Climatic data for the Northwest Atlantic: the position of the shelf/slope front and the northern boundary of the Gulf Stream between $50^{\circ} \mathrm{W}$ and $75^{\circ} \mathrm{W}, 1973-1992$. Can. Data Rep. Hydrogr. Ocean Sci. No. 125.

Gunst, R.F. 1995. Estimating spatial correlations from spatial-temporal meteorological data. Climate, 8: 2454-2470.

Hilborn, R., and Walters, C.J. 1992. Quantitative fisheries stock assessment: choice, dynamics and uncertainty. Chapman and Hall, New York.

Horn, M.H. 1972. The amount of space available for marine and freshwater fishes. Fish. Bull. U.S. 70: 1295-1298.

Kawasaki, T. 1992. Climate-dependent fluctuations in the Far Eastern sardine population and their impacts on fisheries and society. In Climate variability, climate change, and fisheries. Edited by M.H. Glantz. Cambridge University Press, Cambridge, U.K. pp. $325-355$

Koslow, J.A., Thompson, K.R., and Silvert, W. 1987. Recruitment to Northwest Atlantic cod (Gadus morhua) and haddock (Melanogrammus aeglefinus) stocks: influence of stock size and climate. Can. J. Fish. Aquat. Sci. 44: 26-39. 
Lasker, R. 1975. Field criteria for survival of anchovy larvae: the relation between inshore chlorophyll maximum layers and successful first feeding. Fish. Bull. U.S. 73: 453-462.

Leggett, W.G., and DeBlois, E. 1994. Recruitment in marine fishes: is it regulated by starvation and predation in the egg and larval stages? Neth. J. Sea Res. 32: 119-134.

Lehtonen, H., and Lappalainen, J. 1995. The effects of climate on the year-class variations of certain freshwater species. In Climate change and northern fish populations. Edited by R.J. Beamish. Can. Spec. Publ. Fish. Aquat. Sci. No. 121. pp. 37-44.

Magnuson, J.J., Benson, B.J., and Kratz, T.K. 1990. Temporal coherence in the limnology of a suite of lakes in Wisconsin, U.S.A. Freshwater Biol. 23: 145-159.

Mann, K.H. 1993. Physical oceanography, food chains, and fish stocks: a review. ICES J. Mar. Sci. 50: 105-119.

Mills, E.L., Forney, J.L., and Wagner, K.J. 1987. Fish predation and its cascading effect on the Oneida Lake food chain. In Predation: direct and indirect impacts on aquatic communities. Edited by W.C. Kerfoot and A. Sih. University Press of New England, Hanover, N.H. pp. 118-131.

Myers, R.A., Blanchard, W., and Thompson, K.R. 1990. Summary of North Atlantic fish recruitment 1942-1987. Can. Tech. Rep. Fish. Aquat. Sci. No 1743.
Myers, R.A., Barrowman, N.J., and Thompson, K.R. 1995a. Synchrony of recruitment across the North Atlantic: an update. ICES J. Mar. Sci. 52: 103-110.

Myers, R.A., Bridson, J., and Barrowman, N.J. 1995b. Summary of worldwide stock and recruitment data. Can. Tech. Rep. Fish. Aquat. Sci. No. 2024.

Myers, R.A., Mertz, G., and Barrowman, N.J. 1995c. Spatial scales of variability in cod recruitment in the North Atlantic. Can. J. Fish. Aquat. Sci. 52: 1849-1862.

Templeman, W. 1972. Year-class success in some North Atlantic stocks of cod and haddock. Int. Comm. Northwest Atl. Fish. Spec. Publ. No. 8.

Thompson, K.R., Loucks, R.H., and Trites, R.W. 1988. Sea surface temperature variability in the shelf-slope region of the Northwest Atlantic. Atmos.-Ocean, 26: 282-299.

Verity, P.G., and Smetacek, V. 1996. Organism life cycles, predation, and the structure of marine pelagic ecosystems. Mar. Ecol. Prog. Ser. 130: 277-293.

Wooster, W.S., and Bailey, K.M. 1989. Recruitment of marine fishes revisited. In Effects of ocean variability on recruitment and an evaluation of parameters used in stock assessment models. Edited by R.J. Beamish and G.A. McFarlane. Can. Spec. Publ. Fish. Aquat. Sci. No. 108. pp. 153-159. 